\title{
Review Article: Posterior Tibial Nerve Stimulation in Fecal Incontinence: A Systematic Review and Meta-Analysis
}

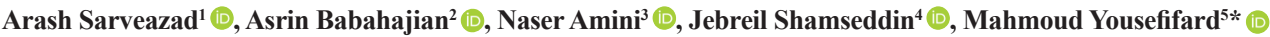 \\ 1. Colorectal Research Center, Iran University of Medical Sciences, Tehran, Iran. \\ 2. Liver and Digestive Research Center, Research Institute for Health Development, Kurdistan University of Medical Sciences, Sanandaj, Iran. \\ 3. Cellular and Molecular Research Center, Iran University of Medical Sciences, Tehran, Iran. \\ 4. Molecular Medicine Research Center, Hormozgan Health Institute, Department of Parasitology, Faculty of Medicine, Hormozgan University of \\ Medical Sciences, Bandar Abbas, Iran. \\ 5. Physiology Research Center, Iran University of Medical Sciences, Tehran, Iran.
}

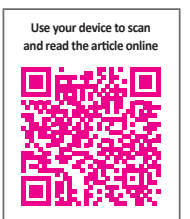

Citation: Sarveazad, A., Babahajian, A., Amini, N., Shamseddin, J., \& Yousefifard, M. (2019). Posterior Tibial Nerve Stimulation in Fecal Incontinence: A Systematic Review and Meta-Analysis. Basic and Clinical Neuroscience, 10(5), 419-432. http:// dx.doi.org/10.32598/bcn.9.10.290

doi http://dx.doi.org/10.32598/bcn.9.10.290

Article info:

Received: 29 Apr 2018

First Revision: 15 May 2018

Accepted: 28 Sep 2018

Available Online: 01 Sep 2019

Keywords:

Fecal incontinence,

Tibial nerve, Electrical nerve stimulation, Tibial neuromodulation

\section{A B S T RA C T}

Introduction: The present systematic review and meta-analysis aims to investigate the role of Posterior Tibial Nerve Stimulation (PTNS) in the control of Fecal Incontinence (FI)

Methods: Two independent reviewers extensively searched in the electronic databases of Medline, Embase, Cochrane Central Register of Controlled Trials (CENTRAL), Web of Science, CINAHL, and Scopus for the studies published until the end of 2016. Only randomized clinical trials were included. The studied outcomes included FI episodes, FI score, resting pressure, squeezing pressure, and maximum tolerable pressure. The data were reported as Standardized Mean Differences (SMD) with 95\% confidence interval.

Results: Five articles were included in the present study (249 patients under treatment with PTNS and 239 in the sham group). Analyses showed that PTNS led to a significant decrease in the number of FI episodes ( $\mathrm{SMD}=-0.38 ; 95 \% \mathrm{CI}$ : $-0.67-0.10 ; \mathrm{P}=0.009)$. Yet, it did not have an effect on FI score (SMD $=0.13 ; 95 \% \mathrm{CI}$ : $-0.49-0.75 ; \mathrm{P}=0.68)$, resting pressure $(\mathrm{SMD}=0.12$; 95\% CI: $-0.14-0.37 ; \mathrm{P}=0.67$ ), squeezing pressure ( $\mathrm{SMD}=-0.27 ; 95 \% \mathrm{CI}:-1.03-0.50 ; \mathrm{P}=0.50$ ), and maximum tolerable pressure $(\mathrm{SMD}=-0.10 ; 95 \% \mathrm{CI}$ : $-0.40-0.24 ; \mathrm{P}=0.52$ ).

Conclusion: Based on the results, it seems that the prescription of PTNS alone cannot significantly improve FI.

\section{* Corresponding Author:}

Mahmoud Yousefifard, PhD.

Address: Physiology Research Center, Iran University of Medical Sciences, Tehran, Iran.

Tel: +98 (939) 1573164

E-mail: yousefifard20@gmail.com 


\section{Highlights}

- Posterior tibial nerve stimulation can lead to a significant decrease in the number of fecal incontinence episodes;

- Posterior tibial nerve stimulation have no effect on fecal incontinence score, resting pressure, squeezing pressure and maximum tolerable pressure;

- The prescription of posterior tibial nerve stimulation alone cannot significantly improve fecal incontinence.

\section{Plain Language Summary}

Fecal Incontinence (FI) is a common and important disorder that affects more than $10 \%$ of adults. Although the operation is considered an essential treatment strategy in managing and treating FI, recently, a systematic review has indicated that there is not enough evidence to support operation as a clinical treatment in adults. Therefore, alternative or adjunctive treatments may be needed. Posterior Tibial Nerve Stimulation (PTNS) is an option for treatment that recent studies have indicated its high effectiveness. PTNS is low-cost and easy to use without anesthesia; however, there is still an ongoing controversy regarding PTNS in FI treatment. In this regard, the present systematic review and metaanalysis aimed at reaching a general conclusion regarding the role of PTNS in the control of FI. For this purpose, we searched for related papers indexed in Medline, Embase, Cochrane Central Register of Controlled Trials (CENTRAL), Web of Science, CINAHL, and Scopus databases. Finally, 5 articles were included in the present study. Analyses showed that PTNS led to a significant decrease in the number of FI episodes, but it had no effect on FI score, resting pressure, squeezing pressure, and maximum tolerable pressure. based on these results, it seems that the prescription of PTNS alone cannot lead to a significant improvement in FI.

\section{Introduction}

elvic floor disorders are currently regarded as one of the delicate problems worldwide since they not only cause health issues for the patient, but also in most cases they are not socially accepted and lead to the isolation of the patient. These problems harm the quality of life, and its high prevalence, especially in postpartum women, made it a social stigma (Biemans \& van Balken, 2013).

Fecal Incontinence (FI) is a common and important disorder that affects more than $10 \%$ of adults (Rockwood et al., 2000; Rockwood et al., 1999). FI occurs because of $i$. anatomical defect such as obstetric and surgical rupture, congenital anomalies, and trauma or, ii. anal sphincter dysfunction, including rectum prolapse, constipation, neuropathy, and inflammatory bowel disease (Kamm, 1998). Primary treatments include conservative measures such as drug therapy and physiotherapy (pelvic floor training and biofeedback) (Madoff, Parker, Varma, \& Lowry, 2004; Norton, Cody, \& Hosker, 2006). Besides, surgical procedures (Madoff, 2004), the injection of biological agents (Malouf, Vaizey, Norton, \& Kamm, 2001), artificial sphincter (Wong et al., 2002), and cell therapy (Sarveazad et al., 2017) like other tissues (Amini et al., 2016; Babahajian, Bahardoost, \& Sarveazad,
2018; Babahajian, Shamseddin, \& Sarveazad, 2017; Faghihi et al., 2015; Sarvandi et al., 2015; Sarveazad et al., 2017; Sarveazad et al., 2014; Yousefifard, Nasirinezhad, et al., 2016) are performed. Although the operation is considered an essential treatment strategy in managing and treating FI, recently, a systematic review has indicated that there is not enough evidence to support operation as a clinical treatment in adults. The study states that surgical methods are more invasive and accompanied by more serious side effects and without sufficient data on the long-term outcomes of this method (Forte et al., 2016). Therefore, alternative or adjunctive treatments may be needed.

Currently, the direct stimulation of pelvic nerves (such as sacral nerve) or indirect stimulation (such as of tibial nerve) is considered the second line of treatment in patients that have not responded to other approaches. Although the mechanism of nerve stimulation in FI management is unknown, the engagement of higher cortical centers and increased somatosensory representation of the anal region in the cortex, as well as higher consciousness of the brain regarding fecal continence, are possible mechanisms (George et al., 2012; Hotouras et al., 2012).

The stimulation of the sacral nerve was one of the first non-operation techniques used for the treatment of FI. 
Studies show that half of the patients will completely cure over 10 years (George et al., 2012; Matzel, Stadelmaie, Gall, \& Hohenfellner, 1995). However, this method is not available in most clinics because of the high cost of the treatment and the need for high skill and experience of the therapist.

Posterior Tibial Nerve Stimulation (PTNS) is another option that recent studies have indicated its high effectiveness (Bondurri, Maffioli, \& Danelli, 2015; de Groat \& Tai, 2015; Edenfield, Amundsen, Wu, Levin, \& Siddiqui, 2015; Giani \& Musco 2015; Grossi et al., 2015; Gupta, Ehlert, Sirls, \& Peters, 2015; Jiménez-Toscano et al., 2015; Kelly, Radley, \& Brown, 2016; Lecompte, Hery, Guys, \& Louis-Borrione, 2015; Lopez-Delgado et al., 2014; Marti \& Maurus, 2014; Moya et al., 2016; Pena Ros et al., 2016; Sucar-Romero, Escobar-del Barco, Rodriguez-Colorado, \& Gorbea-Chavez, 2014; Wexner, 2015). Although there is still an ongoing controversy regarding PTNS in FI treatment, PTNS is low cost and easy to operate without anesthesia (Hotouras et al., 2014; Hotouras et al., 2012). Therefore, a general conclusion is hard to reach at this time.

One way to overcome this problem is the performance of a systematic review and meta-analysis of the existing data. Although a systematic review was carried out in 2012 in this regard, it included only 7 studies. Researchers of the mentioned review claimed that the few numbers of studies, the presence of bias, and high heterogeneity in the existing data prevented reaching a conclusion about the effectiveness of PTNS in FI (Biemans \& van Balken, 2013). Therefore, the present systematic review and meta-analysis aimed at reaching a general conclusion regarding the role of PTNS in the control of FI.

\section{Methods}

\section{Study design}

The present study was designed based on the guideline of doing a meta-analysis of clinical trials in human studies (Cochrane). The data gathering tool in the present study was a checklist for summarizing the extracted data based on PRISMA guidelines. The method of doing the study and analyzing the data has been explained in detail in the previous meta-analyses of the researchers (Ahmadi \& Yousefifard, 2017; Ebrahimi et al., 2014; Ghea lichkhani et al., 2016; Hassanzadeh-Rad et al., 2016; Hosseini et al., 2017; Hosseini, Yousefifard, Aziznejad, \& Nasirinezhad, 2015; Hosseini et al., 2015; Izadi, et al., 2016; Izadi et al., 2016; Mostafa, Mahmoud, Heia dar, \& Farinaz, 2015; Nakhjavan-Shahraki et al., 2017; Nakhjavan-Shahraki, Yousefifard, Oraii, Sarveazad, \& Hosseini, 2017; Nakhjavan-Shahraki et al., 2018; Nak sirinezhad, Hosseini, Karami, Yousefifard, \& Janzadeh, 2016; Rahimi-Movaghar et al., 2016; Safari et al., 2016; Sarveazad et al., 2017; Yousefifard et al., 2016; Yousefifard, et al., 2016; Yousefifard et al., 2017).

\section{Search strategy}

Two independent reviewers carried out an extensive search in the electronic databases of Medline, Embase, Cochrane Central Register of Controlled Trials (CENTRAL), Web of Science, CINAHL, and Scopus until

Table 1. Queries used in Medline, Embase, and Scopus databases

\begin{tabular}{|c|c|}
\hline Database & Search Terms \\
\hline Medline & 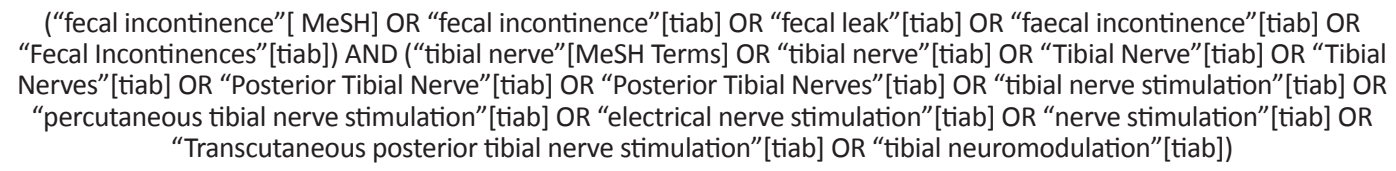 \\
\hline Embase & 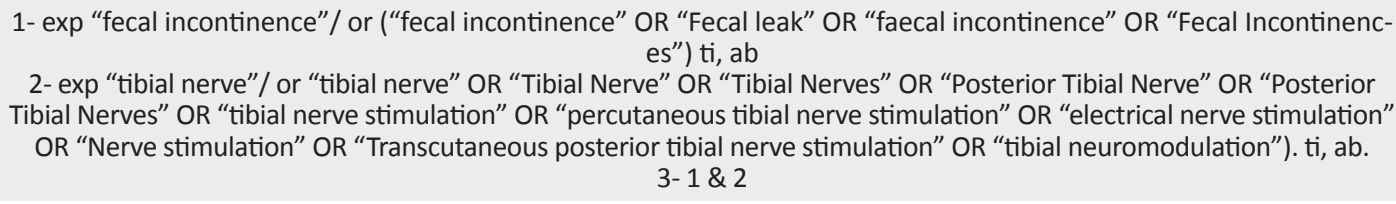 \\
\hline Scopus & $\begin{array}{c}\text { ( ( TITLE-ABS-KEY (fecal incontinence) OR TITLE-ABS-KEY (fecal leak) OR TITLE-ABS-KEY (leak, fecal) OR TITLE-ABS-KEY } \\
\text { (fecal incontinences) OR TITLE-ABS-KEY ( incontinence, fecal)) ) AND ( ( TITLE-ABS-KEY (tibial nerve) OR TITLE-ABS-KEY } \\
\text { (nerve, tibial) OR TITLE-ABS-KEY (tibial nerves) OR TITLE-ABS-KEY (posterior tibial nerve) OR TITLE-ABS-KEY (posterior } \\
\text { tibial nerves) OR TITLE-ABS-KEY (tibial nerve stimulation) OR TITLE-ABS-KEY (percutaneous tibial nerve stimulation) OR } \\
\text { TITLE-ABS-KEY (electrical nerve stimulation) OR TITLE-ABS-KEY (nerve stimulation) OR TITLE-ABS-KEY (transcutaneous } \\
\text { posterior tibial nerve stimulation) OR TITLE-ABS-KEY (tibial neuromodulation) ) ) }\end{array}$ \\
\hline
\end{tabular}


the end of 2016. The search strategy was based on the words presented in Table 1. The keywords were selected to be as broad as possible to avoid missing any study. Although in the present meta-analysis, only human studies are included, the human filter was not applied to the search strategy to avoid mistakenly excluding a study. The applied keywords were selected, using MeSH from the PubMed database, EMTREE network of Embase database, and searching in the titles of the related articles found.

To find additional articles or unpublished data, we also did a hand-search in the list of relevant studies and related journals. In addition to search in the gray literature, 3 strategies were considered. First, a search was done in the section of the dissertation of the ProQuest database. Second, to find the unpublished or under-evaluation data, the authors of the related articles were contacted. Finally, Google and Google Scholar search engines were used to find additional references. In cases that the data could not be extracted, the article authors were contacted. In cases that the corresponding author did not respond to the first email, a reminder email was sent. If there were no response, another reminder email would be sent (with a one-week interval). If there were no response in the third stage, other authors of the article would be contacted, using social networks such as ResearchGate and LinkedIn to provide the researchers with the required data.

\section{Inclusion and exclusion criteria}

In the present study, the randomized clinical trials that had evaluated the role of PTNS in FI were included. Controlled studies are defined as studies that have a control group without PTNS (operation alone or control group) in addition to the group that underwent PTNS. Adults (age $>18$ years old) were selected as the study population. The studies that had evaluated the motor function, ability to control bowel movements and anal sphincter pressure were included. Articles in which the researcher was not blind to the treatment group were excluded from the study. Besides, case report studies were excluded. The absence of a control or placebo group was also considered as another exclusion criterion.

\section{Quality assessment and data extraction}

The results of the search in the literature were combined, and duplicate studies were removed, using EndNote (version X7, Thomson Reuters, 2015) software. In the second phase, during the primary screening, unrelated studies were eliminated. The abstracts of the extracted references were evaluated by 2 independent reviewers and recorded in the data extraction form and, if rejected, the reason would be mentioned. In case of disagreement between the 2 reviewers, the third reviewer studied the data and solved the disagreement by discussing. The extracted data included information regarding study design, sample characteristics, and control group (age, sex, and mechanism of FI), number of samples evaluated, outcome (FI scores and anal sphincter pressures), and probable biases. When the outcomes and studied measures were reported at various times, the last evaluation time was included in the study.

\section{Data synthesis}

The evaluated outcomes consisted of FI episodes, FI scores, resting pressure, squeezing pressure, and maximum tolerable pressure. The data were summarized as mean and standard deviation and entered into the statistical software. The quality of studies was assessed using the guidelines suggested by Cochrane (Agency for Healthcare Research and Quality, 2012). To evaluate the agreement between the 2 reviewers, inter-rater reliability was appraised regarding the quality assessment of the studies (98\%). In case of disagreement, it was solved by discussing it with the third reviewer.

\section{Data analysis}

Statistical analysis was done with STATA version 14.0 (Stata Corporation, College Station, TX). Heterogeneity among the studies was evaluated using the Chi-square and $\mathrm{I} 2$ tests, and a P value of less than 0.1 was considered significant (showing heterogeneity). If the data were homogeneous, the fixed-effect model would be used. In cases that the cause of heterogeneity was not known, the random effect model was applied. Finally, the results of the studies were pooled, and the overall effect size was given. It is worth noting that meta-analysis was done when the associated data were reported by at least 3 studies. The funnel plot and Egger's tests were applied for identifying publication bias (Egger, Smith, Schneider, \& Minder, 1997).

\section{Results}

\section{Characteristics of the included studies}

During the initial search, after removing the duplicate articles, 1572 articles were screened. The full text of 56 articles was read. Finally, 5 articles were entered into the present study (Bouguen et al., 2014; George et al., 2013; Knowles et al., 2015; Leroi et al., 2012; Youssef et al., 2015) (Figure 1). These 5 articles included 6 independent experiments. One study (Leroi et al., 2012) had 2 separate experiments. 


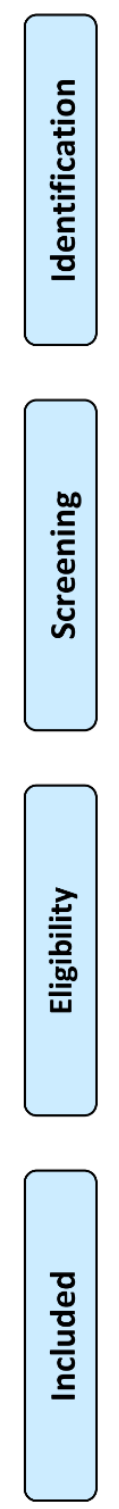

$$
\begin{gathered}
\text { Records identified through database } \\
\text { searching } \\
(\mathrm{n}=2193)
\end{gathered}
$$

Additional records identified through other sources $(n=2)$

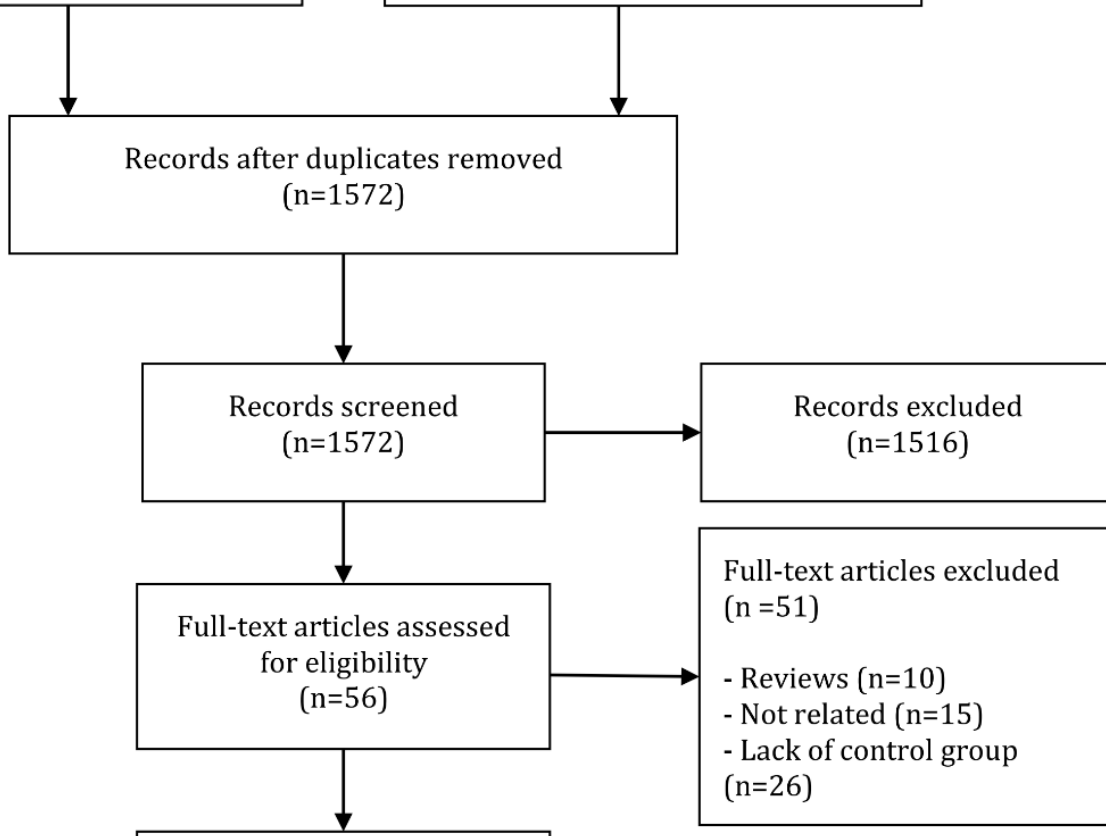

Studies included in qualitative synthesis $(n=5)$

Figure 1. Flowchart of the present meta-analysis

All studies were clinical trials. Stimulation type was transcutaneous in 2 studies (Bouguen et al., 2014; Leroi et al., 2012), percutaneous in 2 (Knowles et al., 2015; Youssef et al., 2015), and both in 1 (George et al., 2013). These studies included the data of 488 patients; 249 patients were treated with PTNS, and 239 were in the control group. The mean age of the included patients was 56.6 years, and $73.0 \%$ of the patients were female. The studies had evaluated various outcomes. Resting pressure was evaluated in 4 experiments, squeezing pressure in 5 experiments, maximum tolerable pressure in 3 experiments, incontinence score in 5 experiments, and FI episodes in 4 experiments. Table 2 presents a summary of the data found in the included articles.

\section{Risk of bias}

In the present study, there was no publication bias. According to Egger test (Coefficient $=-0.06 ; \mathrm{P}=0.96$ ) and Begg's test $(\mathrm{Z}=-0.8 ; \mathrm{P}=0.40$ ), no publication bias was detected (Figure 2 ). The risk of bias was low in all studies (Figure 3).

\section{Meta-analysis}

\section{FI episodes}

In evaluating the effect of PTNS on FI episodes, 4 experiments were included (George et al., 2013; Knowles et al., 2015; Leroi et al., 2012). Heterogeneity was not present among the studies ( $\mathrm{I} 2=32.8 \% ; \mathrm{P}=0.22$ ). Analyses showed that PTNS significantly decreased the num- 
Table 2. Summary of included studies

\begin{tabular}{|c|c|c|c|c|c|c|c|c|c|}
\hline Author, Year & Blinding & $\begin{array}{l}\text { Stimulation } \\
\text { Type }\end{array}$ & $\begin{array}{l}\text { Stimula- } \\
\text { tion Fre- } \\
\text { quency }\end{array}$ & $\begin{array}{l}\text { Session } \\
\text { Duration } \\
\text { (min) }\end{array}$ & $\begin{array}{l}\text { Session } \\
\text { Number }\end{array}$ & $\begin{array}{l}\text { Sample size } \\
\text { (control/ } \\
\text { case) }\end{array}$ & Mean age (y) & $\begin{array}{c}\text { Sex } \\
\text { (male, } \\
\%)\end{array}$ & $\begin{array}{l}\text { Assessed Out- } \\
\text { come }\end{array}$ \\
\hline 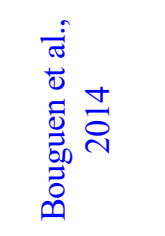 & $\begin{array}{l}\frac{0}{.0} \\
\frac{0}{0} \\
\frac{0}{0} \\
\frac{0}{0} \\
0\end{array}$ & $\begin{array}{l}\text { Percutane- } \\
\text { ous }\end{array}$ & 10 & 20 & 300 & $9 / 10$ & 64.7 & 5.26 & $\begin{array}{l}\text { Squeezing pres- } \\
\text { sure }\end{array}$ \\
\hline 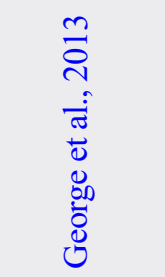 & $\begin{array}{l}\frac{.0}{\bar{c}} \\
\frac{0}{0} \\
\frac{0}{00} \\
i n\end{array}$ & $\begin{array}{l}\text { Percutane- } \\
\text { ous and } \\
\text { transcutane- } \\
\text { ous }\end{array}$ & 20 & 30 & 50 & $8 / 22$ & 57 & 6.67 & $\begin{array}{l}\text { Fl episodes, } \\
\text { incontinence } \\
\text { scores, resting } \\
\text { pressure, squeez- } \\
\text { ing pressure, } \\
\text { maximum toler- } \\
\text { able volume }\end{array}$ \\
\hline 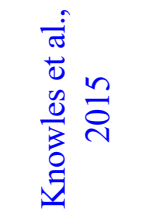 & 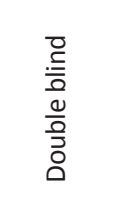 & $\begin{array}{l}\text { Transcutane- } \\
\text { ous }\end{array}$ & 10 & 30 & 12 & 112 / 115 & 58 & 9.69 & $\begin{array}{l}\text { Fl episodes, } \\
\text { incontinence } \\
\text { scores }\end{array}$ \\
\hline 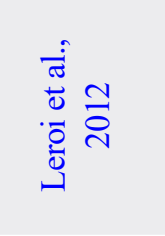 & $\begin{array}{l}\frac{0}{. \frac{1}{0}} \\
\frac{0}{0} \\
\frac{0}{0} \\
0\end{array}$ & $\begin{array}{l}\text { Percutane- } \\
\text { ous }\end{array}$ & 10 & 20 & 90 & 65 / 66 & 60 & 9.92 & $\begin{array}{l}\text { Fl episodes, } \\
\text { incontinence } \\
\text { scores, resting } \\
\text { pressure, squeez- } \\
\text { ing pressure, } \\
\text { maximum toler- } \\
\text { able volume }\end{array}$ \\
\hline 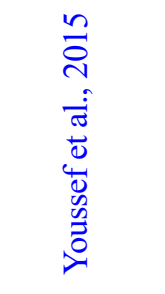 & $\begin{array}{l}\frac{0}{5} \\
\frac{.0}{0} \\
\frac{0}{20} \\
\frac{\stackrel{5}{n}}{n}\end{array}$ & $\begin{array}{l}\text { Transcutane- } \\
\text { ous }\end{array}$ & 10 & 20 & 12 & 37 / 36 & 44.2 & 54.79 & $\begin{array}{l}\text { Incontinence } \\
\text { scores, resting } \\
\text { pressure, squeez- } \\
\text { ing pressure }\end{array}$ \\
\hline
\end{tabular}

$\overline{\mathrm{FI}}=$ Fecal incontinence

NEURSCIENCE

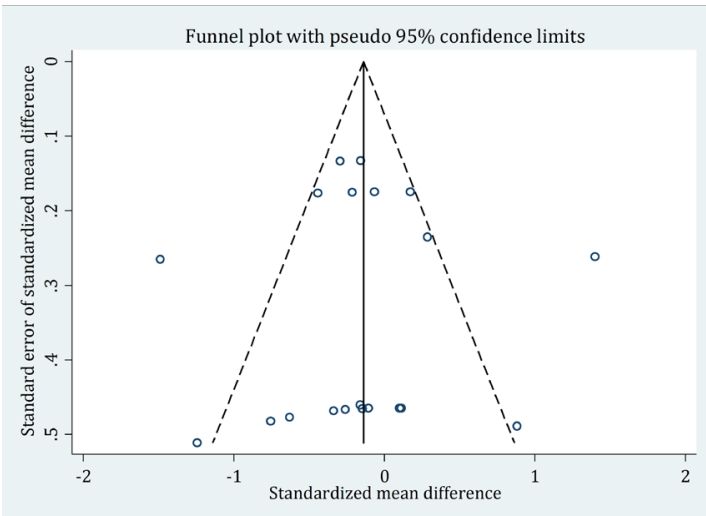

Figure 2. Assessment of publication bias based on the Egger test and Egger funnel plot 


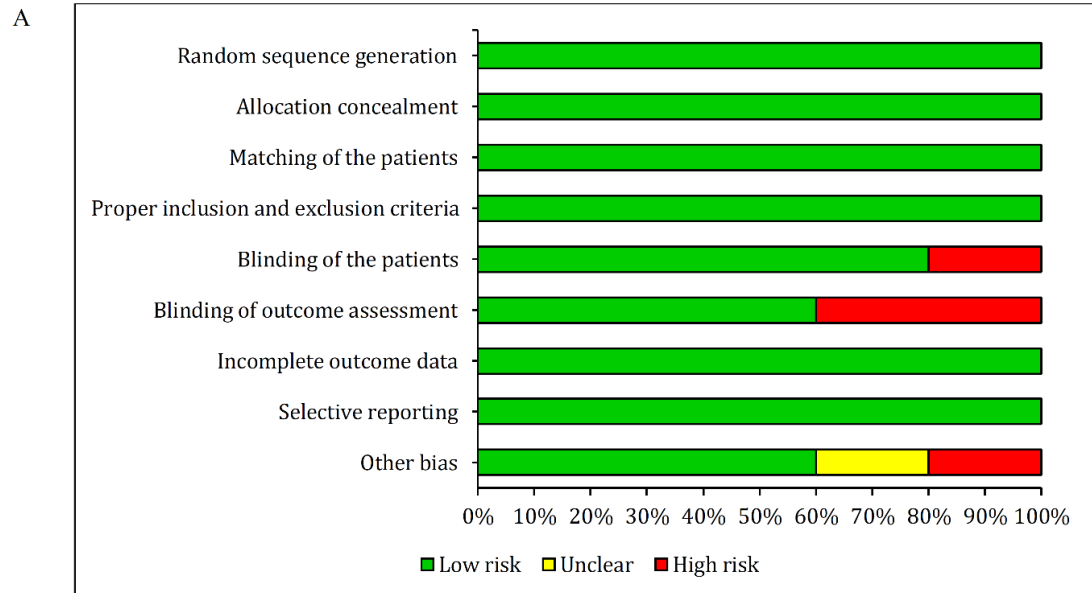

B

\begin{tabular}{|c|c|c|c|c|c|}
\hline $\begin{array}{cl}\oplus & \text { Low risk } \\
\ominus & \text { High risk } \\
\text { ? } & \text { Unclear }\end{array}$ & 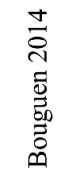 & 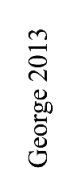 & $\begin{array}{l}n \\
\stackrel{0}{1} \\
0 \\
0 \\
0 \\
0 \\
0 \\
0\end{array}$ & 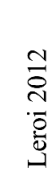 & 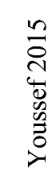 \\
\hline Random sequence generation & $\oplus$ & $\oplus$ & $\oplus$ & $\oplus$ & $\oplus$ \\
\hline Allocation concealment & $\oplus$ & $\oplus$ & $\oplus$ & $\oplus$ & $\oplus$ \\
\hline Matching of the patients & $\oplus$ & $\oplus$ & $\oplus$ & $\oplus$ & $\oplus$ \\
\hline Proper inclusion and exclusion criteria & $\oplus$ & $\oplus$ & $\oplus$ & $\oplus$ & $\oplus$ \\
\hline Blinding of patients & $\oplus$ & $\oplus$ & $\oplus$ & $\oplus$ & $\ominus$ \\
\hline Blinding of outcome assessment & $\oplus$ & $\Theta$ & $\ominus$ & $\oplus$ & $\oplus$ \\
\hline Incomplete outcome data & $\oplus$ & $\oplus$ & $\oplus$ & $\oplus$ & $\oplus$ \\
\hline Selective reporting & $\oplus$ & $\oplus$ & $\oplus$ & $\oplus$ & $\oplus$ \\
\hline Other bias & $\oplus$ & $\oplus$ & ? & $\oplus$ & $\theta$ \\
\hline
\end{tabular}

Figure 3. Risk of bias graph (A) and summary (B) in the included studies based on reviewers' judgments

NEUROSCIENCE

ber of FI episodes in patients with FI (SMD $=-0.38 ; 95 \%$ CI: -0.67-0.10; $\mathrm{P}=0.009$ ) (Figure 4).

Incontinence score

Five experiments were entered in this section (George et al., 2013; Knowles et al., 2015; Leroi et al., 2012; Youssef et al., 2015). The initial evaluation indicated the presence of significant heterogeneity among studies ( $\mathrm{I} 2=88.0 \% ; \mathrm{P}<0.0001)$. It should be noted that PTNS did not have any effect on the improvement of incontinence score in patients with FI (SMD $=0.13$; 95\% CI: -0.49 $0.75 ; \mathrm{P}=0.68$ ) (Figure 4).

\section{Resting pressure}

The data of 4 experiments were included in this section (George et al., 2013; Leroi et al., 2012; Youssef et al., 2015). It is worth mentioning that there was no heterogeneity in this regard $(\mathrm{I} 2=28.8 \% ; \mathrm{P}=0.24)$. The find- ings showed that using PTNS does not have any effect on the improvement of resting pressure in patients with FI (SMD $=0.12 ; 95 \%$ CI: $-0.14-0.37 ; \mathrm{P}=0.67$ ) (Figure 4).

\section{Squeezing pressure}

Considering the data provided in 5 experiments (Bouguen et al., 2014; George et al., 2013; Leroi et al., 2012; Youssef et al., 2015), there was significant heterogeneity among the studies ( $2=85.5 \% ; \mathrm{P}<0.0001)$. Analyses showed that using PTNS did not lead to more improvement in squeezing pressure of patients with FI compared to standard treatment (SMD $=-0.27 ; 95 \% \mathrm{CI}:-1.03-0.50$; $\mathrm{P}=0.50$ ) (Figure 4).

\section{Maximum tolerable pressure}

Three experiments were included in this section (George et al., 2013; Leroi et al., 2012) did not have heterogeneity $(\mathrm{I} 2=0.0 \% ; \mathrm{P}=0.86)$. Like the previous 2 


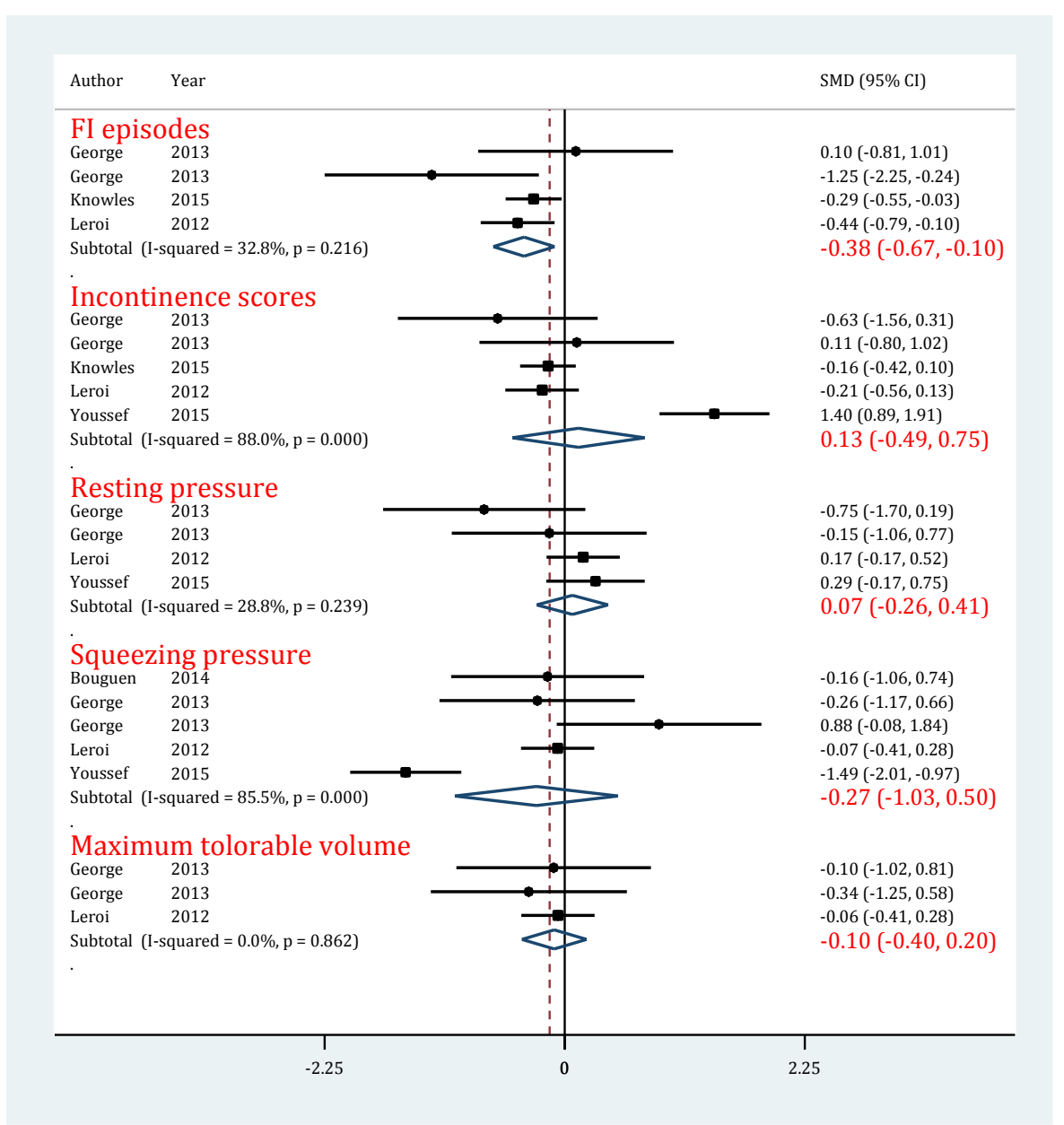

Figure 4. Forrest plot of administrating tibial nerve stimulation in the treatment of fecal incontinence

Abbreviations: $\mathrm{CI}=$ Confidence Interval; $\mathrm{SMD}=$ standardized Mean Difference

outcomes, PTNS did not have an effect on the improvement of maximum tolerable pressure in patients with $\mathrm{FI}$ $(\mathrm{SMD}=-0.10 ; 95 \% \mathrm{CI}:-0.40-0.24 ; \mathrm{P}=0.52$ ) (Figure 4).

\section{Discussion}

In attempts to present less invasive treatment methods for FI, the subjects of neuromodulation, such as the stimulation of the pudendal nerve via an implant (Bock et al., 2010) and direct stimulation of anal sphincter (Herold, Bruch, Höcht, \& Müller, 1988) were proposed, which showed little success. The stimulation of sacral plexus via stimulators is highly successful in treating FI; yet, its high costs (Klingler, Pycha, Schmidbauer, \& Marberger, 2000) and the invasiveness of implanting the stimulator, which is associated with severe side effects (Brazzelli, Murray, \& Fraser, 2006), are among the disadvantages of this method. Therefore, peripheral neuromodulation of sacral plexus, which is a non-invasive method, has been considered. Peripheral neuromodulation has been done since 1983 for the treatment of urinary incontinence, chronic pelvic pains, sexual disorders (McGuire, Zhang, Horwinski, \& Lytton, 1983; Nakamura, Sakurai, Tsujimoto, \& Tada, 1983; Vandoninck et al., 2003), and urologic cases, its success rate is the treatment with drugs and sacral nerve stimulation (Peters et al., 2009). It is explained by the indirect stimulation of the sacral plexus via the posterior tibial nerve, including sensory, motor, and autonomous fibers derived from the fourth and fifth lumbar and the first to the third sacral roots (Cooperberg \& Stoller, 2005).

This systematic review aimed to find an answer to the question: Is PTNS useful for controlling FI or not? Perhaps the simplest mechanism that can be proposed for the effect of PTNS on FI is its effect on motor fibers that feed the anal sphincter, which results in the increased voluntary contractile power of the sphincter. This, in turn, can lead to an improvement in evaluating the measures of FI, including FI episodes and scores, 
maximum tolerable, and squeezing pressure. However, the result of our meta-analysis showed that PTNS can only be effective regarding FI episodes and has no effect on other measures. This finding indicates that various mechanisms are involved. These mechanisms are much more complicated than the direct effect in increased contractile power of sphincter.

Mechanisms by which PTNS improves FI are not fully understood, but in general, it can be said that PTNS leads to rectum sensory nerve stimulation (Michelsen, Buntzen, Krogh, \& Laurberg, 2006; Rosen, Urbarz, Holzer, Novi, \& Schiessel, 2001) and striated sphincter neuromodulation (Shafik, Ahmed, El-Sibai, \& Mostafa, 2003). The effects of this neuromodulation decrease laxity of the anal canal and contraction in the rectum (Shafik et al., 2003; Vaizey, Kamm, Turner, Nicholls, \& Wolosze ko, 1999), increase bloodstream in the rectal mucosa (via stimulation of autonomous fibers) (Emmanuel \& Kamm, 1999), and change the central neurotransmitter environment (Chang et al., 1998; Cooperberg \& Stoller, 2005). The PTNS mechanisms of action in FI can be evaluated in 2 levels: i. central nervous system and, ii. peripheral nervous system. In the central mechanism, since the alternating stimulation of posterior tibial nerve leads to the inhibition of $A \delta$ pain afferent fibers in the spinothalamic tract (Chung, Lee, Hori, Endo, \& Willis, 1984), it is thought that pathologic sensory information (in abnormal passing of urine and stool) and the consciousness of the pathological situation are inhibited. Therefore, central nervous system responses regarding bowel disorders are adjusted (Bemelmans, Mundy, \& Craggs, 1999; de Groat, 1997).

The peripheral mechanism of PTNS is mediated via nerves that originate from the sacral plexus, which innervate the anorectal region. In a mixed nerve (such as the pudendal nerve), the stimulation threshold of various fibers is different. The lowest threshold belongs to the motor fibers of $\mathrm{A} \alpha$ and the highest to $\mathrm{C}$ fibers (transmission of pain). Therefore, when stimulating via an implant, the weakest stimulation activates alpha motor fibers. Then, reflexes are produced after the activation of A $\delta$ fibers, which have a higher threshold. In weak stimulations (like superficial stimulation produced by electrodes during PTNS), although initially $\mathrm{A} \alpha$ motor fibers that feed the external anal sphincter are stimulated, this stimulation is not enough for increasing the pressure of the external anal sphincter and this can be a logical explanation for the result of our study, indicating that PTNS does not affect squeezing pressure (squeezing pressure is $100 \%$ related to the contractile power of the external anal sphincter (Bansal, Sachdeva, Jain, Ranjan, \& Arora, 2013). However, this stimulation may be enough for acti- vating A $\delta$ reflexes (Vaizey et al., 1999). Therefore, enhancing and adjusting these reflexes following PTNS can be a logical explanation for the findings in our study, indicating a decrease in FI episodes. These reflexes include Anorectal Tightening Reflex (ATR) and Gower's reflex.

During the slow filling of the rectum ATR by the contraction of the internal anal sphincter and during rapid rectal filling Gower's reflex via the contraction of the external anal sphincter leads to fecal continence (Shafik, 1993). As mentioned before, sensory fibers such as pain have the highest stimulation threshold for activation; therefore, they are not activated in weak stimulations (Vaizey et al., 1999). As a result, it is no surprise that as the findings of our study show, PTNS does not affect the maximum tolerable volume, which indicates rectal sensation (Kim, 2010).

To sum up, the present study had some strong points and weak points. Among the strong points of the study were extensive search in literature, doing a hand search repeatedly contacting the authors for obtaining information related to the included articles. Another strong point of the current study was including only randomized clinical trials that had a control group. This resulted in; first, a good level of quality of the included trials and, second, minimizing publication bias and heterogeneity among the studies. However, the present study also had some limitations. One of the most important limitations was the inability to do subgroup analysis because of the small number of the included articles. The second limitation of this study was the presence of 2 single-blind studies among 5 studies that were evaluated, which might have caused the bias and be the source of the heterogeneity seen in some of the studied outcomes. Since the subgroup analysis was absent, the effect of variations in blinding the studies on the results could not be assessed.

\section{Conclusion}

The present meta-analysis attempted to reach a conclusion from the existing studies regarding the effectiveness of PTNS in the treatment of FI. The findings of the present study showed that PTNS only decreased FI episodes, but did affect anal sphincter pressure and FI scores. Therefore, based on these results, it seems that the prescription of PTNS alone cannot lead to a significant improvement in FI. 


\section{Ethical Considerations}

\section{Compliance with ethical guidelines}

All ethical principles were considered in this article.

Funding

This research was supported by the Iran University of Medical Sciences and Health Services grant (Grant number: 95-02-182-28975).

\section{Authors' contributions}

Study designer and data management: Mahmoud Yousefifard, Arash Sarveazad; Data acquisition: Arash Sarveazad, Asrin Babahajian; Data analyzer: Mahmoud Yousefifard, Jebreil Shamseddin; Writing first draft and revising the manuscript: Arash Sarveazad, Asrin Babahajian. All authors approved the final version of the manuscript to be published and are accountable for all aspects of the work.

\section{Conflict of interest}

The authors declared no conflict of interest.

\section{Acknowledgments}

We appreciate Prof. Bahar Mahjoubi for her help in the scientific editing of the paper.

\section{References}

Agency for Healthcare Research and Quality. (2011). Methods guide for effectiveness and comparative effectiveness reviews. Fishers: Agency for Healthcare Research and Quality.

Ahmadi, S., \& Yousefifard, M. (2017). Accuracy of pediatric emergency care applied research network rules in prediction of clinically important head injuries; A systematic review and meta-analysis. International Journal of Pediatrics, 5(12), 6285-300.

Amini, N., Vousooghi, N., Hadjighassem, M., Bakhtiyari, M., Mousavi, N., Safakheil, H., et al. (2016). Efficacy of human adipose tissue-derived stem cells on neonatal bilirubin encephalopathy in rats. Neurotoxicity Research, 29(4), 514-24. [DOI:10.1007/s12640-016-9599-3] [PMID]

Babahajian, A., Bahardoost, M., \& Sarveazad, A. (2018). Stem cell therapy in anal fistula: A mini review. Journal of Medical Physiology, 3(1), 1-3.

Babahajian, A., Shamseddin, J., \& Sarveazad, A. (2017). Stem cell therapy in fecal incontinence: A narrative review. The Journal of Physiology, 2(1), 2-9.
Bansal, N., Sachdeva, M., Jain, P., Ranjan, P., \& Arora, A. (2013) Anorectal manometry: Current techniques and indications. Journal of International Medical Sciences Academy, 26(3), 169-70.

Bemelmans, B. L., Mundy, A. R., \& Craggs, M. D. (1999). Neuromodulation by implant for treating lower urinary tract symptoms and dysfunction. European Urology, 36(2), 81-91. [DOI:10.1159/000067976] [PMID]

Biemans, J. M., \& Van Balken, M. R. (2013). Efficacy and effectiveness of percutaneous tibial nerve stimulation in the treatment of pelvic organ disorders: A systematic review. Neuromodulation, 16(1), 25-34. [DOI:10.1111/j.1525-1403.2012.00504.x] [PMID]

Bock, S., Folie, P., Wolff, K., Marti, L., Engeler, D., \& Hetzer, F (2010). First experiences with pudendal nerve stimulation in fecal incontinence: A technical report. Techniques in Coloproctology, 14(1), 41-4. [DOI:10.1007/s10151-009-0554-7] [PMID]

Bondurri, A., Maffioli, A., \& Danelli, P. (2015). Pelvic floor dysfunction in inflammatory bowel disease. Minerva Gastroenterologica e Dietologica, 61(4), 249-59. [PMID]

Bouguen, G., Ropert, A., Laine, F., Pequin, P., Morcet, J., \& Bretagne, J. F., et al. (2014). Effects of transcutaneous tibial nerve stimulation on anorectal physiology in fecal incontinence: A double-blind placebo-controlled cross-over evaluation. Neurogastroenterology and Motility, 26(2), 247-54. [DOI:10.1111/nmo.12256] [PMID]

Brazzelli, M., Murray, A., \& Fraser, C. (2006). Efficacy and safety of sacral nerve stimulation for urinary urge incontinence: A systematic review. Journal of Urology, 175(3), 835-41 [DOI:10.1016/S0022-5347(05)00326-5]

Chang, C. J., Huang, S. T., Hsu, K., Lin, A., Stoller, M. L., \& Lue, T. F. (1998). Electroacupuncture decreases c-fos expression in the spinal cord induced by noxious stimulation of the rat bladder. Journal of Urology, 160(6), 2274-9. [DOI:10.1097/00005392199812010-00099]

Chung, J., Lee, K., Hori, Y., Endo, K., \& Willis, W. (1984). Factors influencing peripheral nerve stimulation produced inhibition of primate spinothalamic tract cells. Pain, 19(3), 277-93. [DOI:10.1016/0304-3959(84)90005-8]

Cooperberg, M. R., \& Stoller, M. L. (2005). Percutaneous neuromodulation. Urologic Clinics of North America, 32(1), 71-8 [DOI:10.1016/j.ucl.2004.09.007] [PMID]

de Groat, W. C. (1997). A neurologic basis for the overactive bladder. Urology, 50(6), 36-52. [DOI:10.1016/S0090-4295(97)005876]

de Groat, W. C., \& Tai, C. (2015). Impact of bioelectronic medicine on the neural regulation of pelvic visceral function Bioelectronic Medicine, 2(1), 25-36. [DOI:10.15424/bioelectronn med.2015.00003] [PMID] [PMCID]

Ebrahimi, A., Yousefifard, M., Kazemi, H. M., Rasouli, H. R., Asady, H., \& Jafari, A. M., et al. (2014). Diagnostic accuracy of chest ultrasonography versus chest radiography for identification of pneumothorax: A systematic review and metaanalysis. Tanaffos, 13(4), 29-40. [PMID] [PMCID]

Edenfield, A. L., Amundsen, C. L., Wu, J. M., Levin, P. J., \& Siddiqui, N. Y. (2015). Posterior tibial nerve stimulation for the treatment of fecal incontinence: A systematic evidence review. Obstetrical and Gynecological Survey, 70(5), 329-41. [DOI:10.1097/OGX.0000000000000171] [PMID] 
Egger, M., Smith, G. D., Schneider, M., \& Minder, C. (1997). Bias in meta-analysis detected by a simple, graphical test. BMJ, 315(7109), 629-34. [DOI:10.1136/bmj.315.7109.629] [PMID] [PMCID]

Emmanuel, A., \& Kamm, M. (1999). Laser doppler measurement of rectal mucosal blood flow. Gut, 45(1), 64-9. [DOI:10.1136/ gut.45.1.64] [PMID] [PMCID]

Faghihi, F., Mirzaei, E., Sarveazad, A., Ai, J., Barough, S. E., \& Lotfi, A., et al. (2015). Differentiation potential of human bone marrow mesenchymal stem cells into motorneuron-like cells on electrospun gelatin membrane. Journal of Molecular Neuroscience, 55(4), 845-53. [DOI:10.1007/s12031-014-0437-x] [PMID]

Forte, M. L., Andrade, K. E., Lowry, A. C., Butler, M., Bliss, D. Z., \& Kane, R. L. (2016). Systematic review of surgical treatments for fecal incontinence. Diseases of the Colon and Rectum, 59(5), 443-69. [DOI:10.1097/DCR.0000000000000594] [PMID]

George, A. T., Kalmar, K., Panarese, A., Dudding, T. C., Nicholls, R. J., \& Vaizey, C. J. (2012). Long-term outcomes of sacral nerve stimulation for fecal incontinence. Diseases of the Colon and Rectum, 55(3), 302-6. [DOI:10.1097/DCR.0b013e3182401ecd] [PMID]

George, A. T., Kalmar, K., Sala, S., Kopanakis, K., Panarese, A. \& Dudding, T. C., et al. (2013). Randomized controlled trial of percutaneous versus transcutaneous posterior tibial nerve stimulation in faecal incontinence. British Journal of Surgery, 100(3), 330-8. [DOI:10.1002/bjs.9000] [PMID]

Ghelichkhani, P., Yousefifard, M., Nazemi, L., Safari, S., Hosseini, M., \& Baikpour, M., et al. (2016). The value of serum $\beta$-subunit of human chorionic gonadotropin level in prediction of treatment response to methotrexate in management of ectopic pregnancy; A systematic review and meta-analysis. International Journal of Pediatrics, 4(9), 3503-18. [DOI:10.22038/ ijp.2016.7409]

Giani, I., \& Musco, S. (2015). Tibial nerve stimulation. Berlin: Springer. [DOI:10.1007/978-3-319-06947-0_9] [PMID] [PMO CID]

Grossi, U., Hotouras, A., Horrocks, E., Allison, M., Chan, C. L., \& Knowles, C. H. (2015). Home-based percutaneous tibial nerve stimulation for fecal incontinence: Is it feasible? Annals of Surgery, 261(1), e1. [DOI:10.1097/SLA.0000000000000887] [PMID]

Gupta, P., Ehlert, M. J., Sirls, L. T., \& Peters, K. M. (2015). Percutaneous tibial nerve stimulation and sacral neuromodulation: An update. Current Urology Reports, 16(2), 1-16. [DOI:10.1007/ s11934-014-0479-1] [PMID]

Hassanzadeh-Rad, A., Yousefifard, M., Katal, S., Asady, H., Fard-Esfahani, A., \& Moghadas Jafari, A., et al. (2016). The value of 18F-fluorodeoxyglucose positron emission tomography for prediction of treatment response in gastrointestinal stromal tumors: A systematic review and meta-analysis. Journal of Gastroenterology and Hepatology, 31(5), 929-35. [DOI:10.1111/ jgh.13247] [PMID]

Herold, A., Bruch, H. P., Höcht, B., \& Müller, G. (1989). Biofeedback training and functional electrostimulation for improving incontinence in children with anal atresia. Langenbecks Archiv fur Chirurgie. Supplement II, Verhandlungen der Deutschen Gesellschaft fur Chirurgie. New York: Deutsche Gesellschaft fur Chirurgie.
Hosseini, M., Yousefifard, M., Ataei, N., Oraii, A., Razaz, J. M., \& Izadi, A. (2017). The efficacy of probiotics in prevention of urinary tract infection in children: A systematic review and meta-analysis. Journal of Pediatric Urology, 13(6), 581-91. [DOI:10.1016/j.jpurol.2017.08.018] [PMID]

Hosseini, M., Yousefifard, M., Aziznejad, H., \& Nasirinezhad, F. (2015). The effect of bone marrow-derived mesenchymal stem cell transplantation on allodynia and hyperalgesia in neuropathic animals: A systematic review with meta-analysis. Biology of Blood and Marrow Transplantation, 21(9), 1537-44. [DOI:10.1016/j.bbmt.2015.05.008] [PMID]

Hosseini, M., Yousefifard, M., Baikpour, M., Rafei, A., Fayaz, M., \& Heshmat, R., et al. (2015). Twenty-year dynamics of hypertension in Iranian adults: Age, period, and cohort analysis. Journal of the American Society of Hypertension, 9(12), 925-34. [DOI:10.1016/j.jash.2015.09.005] [PMID]

Hotouras, A., Murphy, J., Walsh, U., Allison, M., Curry, A., \& Williams, N. S., et al. (2014). Outcome of Percutaneous Tibial Nerve Stimulation (PTNS) for fecal incontinence: A prospective cohort study. Annals of Surgery, 259(5), 939-43. [DOI:10.1097/SLA.0b013e3182a6266c] [PMID]

Hotouras, A., Thaha, M. A., Allison, M. E., Currie, A., Scott, S. M., \& Chan, C. L. (2012). Percutaneous Tibial Nerve Stimulation (PTNS) in females with faecal incontinence: The impact of sphincter morphology and rectal sensation on the clinical outcome. International Journal of Colorectal Disease, 27(7), 927-30. [DOI:10.1007/s00384-011-1405-3] [PMID]

Hotouras, A., Thaha, M., Boyle, D., Allison, M., Currie, A., \& Knowles, C., et al. (2012). Short-term outcome following percutaneous tibial nerve stimulation for faecal incontinence: A single-centre prospective study. Colorectal Disease, 14(9), 1101-5. [DOI:10.1111/j.1463-1318.2011.02906.x] [PMID]

Izadi, A., Yousefifard, M., Nakhjavan-Shahraki, B., Baikpour, M., Mirzay Razaz, J., \& Ataei, N., et al. (2016). Value of plasma/ serum neutrophil gelatinase-associated lipocalin in detection of pediatric acute kidney injury; a systematic review and meta-analysis. International Journal of Pediatrics, 4(11), 3815-36. [DOI:10.22038/ijp.2016.7782]

Izadi, A., Yousefifard, M., Nakhjavan-Shahraki, B., Baikpour, M., Mirzay Razaz, J., \& Hosseini, M. (2016). Diagnostic value of urinary Neutrophil Gelatinase-Associated Lipocalin (NGAL) in detection of pediatric acute kidney injury; A systematic review and meta-analysis. International Journal of Pediatrics, 4(11), 3875-95. [DOI:10.22038/IJP.2016.7783]

Jiménez-Toscano, M., Vega, D., Fernandez-Cebrián, J. M., Valle Martín, B., Jiménez-Almonacid, P., \& Rueda Orgaz, J. A (2015). Efficacy and quality of life after transcutaneous posterior tibial neuromodulation for faecal incontinence. Colorectal Disease, 17(8), 718-23. [DOI:10.1111/codi.12923] [PMID]

Kamm, M. A. (1998). Faecal incontinence. BMI, 316(7130), 528-32. [DOI:10.1136/bmj.316.7130.528] [PMID] [PMCID]

Kelly, S. L., Radley, S. C., \& Brown, S. R. (2016). Does percutaneous tibial nerve stimulation improve global pelvic function in women with faecal incontinence? Colorectal Disease, 18(5), 158-63. [DOI:10.1111/codi.13329] [PMID]

Kim, J. H. (2010). How to interpret conventional anorectal manometry. Journal of Neurogastroenterology and Motility, 16(4) 437-9. [DOI:10.5056/jnm.2010.16.4.437] [PMID] [PMCID] 
Klingler, H., Pycha, A., Schmidbauer, J., \& Marberger, M. (2000). Use of peripheral neuromodulation of the S3 region for treatment of detrusor overactivity: A urodynamic-based study. Urology, 56(5), 766-71. [DOI:10.1016/S0090-4295(00)00727-5]

Knowles, C. H., Horrocks, E. J., Bremner, S. A., Stevens, N., Norton, C., \& O'Connell, P. R., et al. (2015). Percutaneous tibial nerve stimulation versus sham electrical stimulation for the treatment of faecal incontinence in adults (CONFIDeNT): A double-blind, multicentre, pragmatic, parallelgroup, randomised controlled trial. Lancet, 386(10004), 1640-8. [DOI:10.1016/S0140-6736(15)60314-2]

Lecompte, J. F., Hery, G., Guys, J. M., \& Louis-Borrione, C. (2015). Evaluation of transcutaneous electrical posterior tibial nerve stimulation for the treatment of fecal and urinary leaks in children: Preliminary results. Journal of Pediatric Surgery, 50(4), 630-3. [DOI:10.1016/j.jpedsurg.2014.05.033] [PMID]

Leroi, A. M., Siproudhis, L., Etienney, I., Damon, H., Zerbib, F., \& Amarenco, G., et al. (2012). Transcutaneous electrical tibial nerve stimulation in the treatment of fecal incontinence: A randomized trial (Consort 1a). American Journal of Gastroenterology, 107(12), 1888-96. [DOI:10.1038/ajg.2012.330] [PMID]

Lopez-Delgado, A., Arroyo, A., Ruiz-Tovar, J., Alcaide, M. J., Diez, M., \& Moya, P., et al. (2014). Effect on anal pressure of percutaneous posterior tibial nerve stimulation for faecal incontinence. Colorectal Disease, 16(7), 533-7. [DOI:10.1111/ codi.12628] [PMID]

Madoff, R. D. (2004). Surgical treatment options for fecal incontinence. Gastroenterology, 126(2), S48-S54. [DOI:10.1053/j.gass tro.2003.10.015] [PMID]

Madoff, R. D., Parker, S. C., Varma, M. G., \& Lowry, A. C. (2004). Faecal incontinence in adults. Lancet, 364(9434), 621-32. [DOI:10.1016/S0140-6736(04)16856-6]

Malouf, A. J., Vaizey, C. J., Norton, C. S., \& Kamm, M. A. (2001). Internal anal sphincter augmentation for fecal incontinence using injectable silicone biomaterial. Diseases of the Colon and Rectum, 44(4), 595-600. [DOI:10.1007/BF02234337] [PMID]

Marti, L., \& Maurus, C. (2014). Transcutaneous electrical tibial nerve stimulation in the treatment of fecal incontinence: A randomized trial (CONSORT 1a). Urologe, 53(10), 1523-4. [DOI:10.1007/s00120-014-3660-8]

Matzel, K. E., Stadelmaie, U., Gall, F. P., \& Hohenfellner, M. (1995). Electrical stimulation of sacral spinal nerves for treatment of faecal incontinence. Lancet, 346(8983), 1124-7. [DOI:10.1016/S0140-6736(95)91799-3]

McGuire, E., Zhang, S., Horwinski, E., \& Lytton, B. (1983). Treatment of motor and sensory detrusor instability by electrical stimulation. Journal of Urology, 129(1), 78-9. [DOI:10.1016/ S0022-5347(17)51928-X]

Michelsen, H. B., Buntzen, S., Krogh, K., \& Laurberg, S. (2006). Rectal volume tolerability and anal pressures in patients with fecal incontinence treated with sacral nerve stimulation. Diseases of the Colon and Rectum, 49(7), 1039-44. [DOI:10.1007/ s10350-006-0548-8] [PMID]

Mostafa, H., Mahmoud, Y., Heidar, A., \& Farinaz, N. (2015). The effect of bone mesenchymal stem cell transplantation on allodynia and hyperalgesia in neuropathic animals: A systematic review with meta-analysis. Biol Blood Marrow Transplant, 21(9), 1537-44. [DOI:10.1016/j.bbmt.2015.05.008] [PMID]
Moya, P., Parra, P., Arroyo, A., Pena, E., Benavides, J., \& Calpena, R. (2016). Sacral nerve stimulation versus percutaneous posterior tibial nerve stimulation in the treatment of severe fecal incontinence in men. Techniques in Coloproctology, 20(5), 317-9. [DOI:10.1007/s10151-016-1443-5] [PMID]

Nakamura, M., Sakurai, T., Tsujimoto, Y., \& Tada, Y. (1983). [Transcutaneous electrical stimulation for the control of frequency and urge incontinence (Japanese). Hinyokika kiyo. Acta urologica Japonica, 29(9), 1053-9. [PMID]

Nakhjavan-Shahraki, B., Yousefifard, M., Ataei, N., Baikpour, M., Ataei, F., \& Bazargani, B., et al. (2017). Accuracy of cystatin $C$ in prediction of acute kidney injury in children; serum or urine levels: Which one works better? A systematic review and meta-analysis. BMC Nephrology, 18, 120. [DOI:10.1186/ s12882-017-0539-0] [PMID] [PMCID]

Nakhjavan-Shahraki, B., Yousefifard, M., Oraii, A., Sarveazad, A., \& Hosseini, M. (2017). Meta-analysis of neuron specific enolase in predicting pediatric brain injury outcomes. EXCLI Journal, 16, 995-1008. [PMID] [PMCID]

Nakhjavan-Shahraki, B., Yousefifard, M., Rahimi-Movaghar, V., Baikpour, M., Nasirinezhad, F., \& Safari, S., et al. (2018) Transplantation of olfactory ensheathing cells on functional recovery and neuropathic pain after spinal cord injury; systematic review and meta-analysis. Scientific Reports, 8(1), 325. [DOI:10.1038/s41598-017-18754-4] [PMID] [PMCID]

Nasirinezhad, F., Hosseini, M., Karami, Z., Yousefifard, M., \& Janzadeh, A. (2016). Spinal 5-HT3 receptor mediates nociceptive effect on central neuropathic pain; possible therapeutic role for tropisetron. The Journal of Spinal Cord Medicine, 39(2), 212-9. [DOI:10.1179/2045772315Y.0000000047] [PMID] [PMO CID

Norton, C., Cody, J. D., \& Hosker, G. (2006). Biofeedback and/ or sphincter exercises for the treatment of faecal incontinence in adults. Cochrane Database System Reviews, 3(3), Cd002111. [DOI:10.1002/14651858.CD002111.pub2]

Pena Ros, E., Parra Banos, P. A., Benavides Buleje, J. A., Munoz Camarena, J. M., Escamilla Segade, C., \& Candel Arenas, M. F., et al. (2016). Short-term outcome of Percutaneous Posterior Tibial Nerve Stimulation (PTNS) for the treatment of faecal incontinence. Techniques in Coloproctology, 20(1), 19-24. [DOI:10.1007/s10151-015-1380-8] [PMID]

Peters, K. M., MacDiarmid, S. A., Wooldridge, L. S., Leong, F. C., Shobeiri, S. A., \& Rovner, E. S., et al. (2009). Randomized trial of percutaneous tibial nerve stimulation versus extended-release tolterodine: Results from the overactive bladder innovative therapy trial. Journal of Urology, 182(3), 1055-61. [DOI:10.1016/j.juro.2009.05.045] [PMID]

Rahimi-Movaghar, V., Yousefifard, M., Ghelichkhani, P., Baik pour, M., Tafakhori, A., \& Asady, H., et al. (2016). Application of ultrasonography and radiography in detection of hemothorax; A systematic review and meta-analysis. Emergency, 4(3), 116-26. [PMID] [PMCID]

Rockwood, T. H., Church, J. M., Fleshman, J. W., Kane, R. L., Mavrantonis, C., \& Thorson, A. G., et al. (2000). Fecal incontinence quality of life scale. Diseases of the Colon and Rectum, 43(1), 9-16. [DOI:10.1007/BF02237236] [PMID]

Rockwood, T. H., Church, J. M., Fleshman, J. W., Kane, R. L., Mavrantonis, C., \& Thorson, A. G., et al. (1999). Patient and surgeon ranking of the severity of symptoms associated with 
fecal incontinence. Diseases of the Colon and Rectum, 42(12), 1525-31. [DOI:10.1007/BF02236199] [PMID]

Rosen, H. R., Urbarz, C., Holzer, B., Novi, G., \& Schiessel, R. (2001). Sacral nerve stimulation as a treatment for fecal incontinence. Gastroenterology, 121(3), 536-41. [DOI:10.1053/ gast.2001.27120] [PMID]

Safari, S., Yousefifard, M., Hashemi, B., Baratloo, A., Forouzanfar, M. M., \& Rahmati, F., et al. (2016). The value of serum creatine kinase in predicting the risk of rhabdomyolysis-in duced acute kidney injury: A systematic review and metaanalysis. Clinical and Experimental Nephrology, 20(2), 153-61. [DOI:10.1007/s10157-015-1204-1] [PMID]

Sarvandi, S. S., Joghataei, M. T., Parivar, K., Khosravi, M., Sarveazad, A., \& Sanadgol, N. (2015). In vitro differentiation of rat mesenchymal stem cells to hepatocyte lineage. Iranian Journal of Basic Medical Sciences, 18(1), 89-97. [PMID] [PMCID]

Sarveazad, A., Babahajian, A., Bakhtiari, M., Soleimani, M., Behnam, B., \& Yari, A., et al. (2017). The combined application of human adipose derived stem cells and chondroitinase $\mathrm{ABC}$ in treatment of a spinal cord injury model. Neuropeptides, 61, 39-47. [DOI:10.1016/j.npep.2016.07.004] [PMID]

Sarveazad, A., Babahajian, A., Yari, A., Shamseddin, J., \& Yousefifard, M. (2017). Efficacy of neuromodulation in fecal incontinence in children; a systematic review and meta-analysis. International Journal of Pediatrics, 5(12), 6563-77. [DOI:10.22038/ IJP.2017.27713.2397]

Sarveazad, A., Bakhtiari, M., Babahajian, A., Janzade, A., Fallah, A., \& Moradi, F., et al. (2014). Comparison of human adiposederived stem cells and chondroitinase $\mathrm{ABC}$ transplantation on locomotor recovery in the contusion model of spinal cord injury in rats. Iranian Journal of Basic Medical Sciences, 17(9), 685-93. [PMID] [PMCID]

Sarveazad, A., Newstead, G. L., Mirzaei, R., Joghataei, M. T., Bakhtiari, M., Babahajian, A., et al. (2017). A new method for treating fecal incontinence by implanting stem cells derived from human adipose tissue: Preliminary findings of a randomized double-blind clinical trial. Stem Cell Research $\mathcal{E}$ Therapy, 8(1), 40. [DOI:10.1186/s13287-017-0489-2] [PMID] [PMCID]

Shafik, A. (1993). Anorectal tightening reflex: Role in fecal incontinence. European Surgical Research, 25(6), 399-405. [DOI:10.1159/000129308] [PMID]

Shafik, A., Ahmed, I., El-Sibai, O., \& Mostafa, R. (2003). Percutaneous peripheral neuromodulation in the treatment of fecal incontinence. European Surgical Research, 35(2), 103-7. [DOI:10.1159/000069399] [PMID]

Sucar-Romero, S., Escobar-del Barco, L., Rodriguez-Colorado, S., \& Gorbea-Chavez, V. (2014). [Posterior tibial nerve stimulation for pelvic floor dysfunction. Review (Spanish)]. Ginecología y Obstetricia de México, 82(8), 535-46.

Vaizey, C., Kamm, M., Turner, I., Nicholls, R., \& Woloszko, J. (1999). Effects of short term sacral nerve stimulation on anal and rectal function in patients with anal incontinence. Gut, 44(3), 407-12. [DOI:10.1136/gut.44.3.407] [PMID] [PMCID]

Vandoninck, V., Van Balken, M. R., Agró, E. F., Petta, F., Caltagirone, C., \& Heesakkers, J. P., et al. (2003). Posterior tibial nerve stimulation in the treatment of urge incontinence. Neurourology and Urodynamics, 22(1), 17-23. [DOI:10.1002/nau.10036] [PMID]
Wexner, S. D. (2015). Percutaneous tibial nerve stimulation in faecal incontinence. Lancet, 386(10004), 1605-6. [DOI:10.1016/ S0140-6736(15)60508-6]

Wong, W. D., Congliosi, S. M., Spencer, M. P., Corman, M. L., Tan, P., \& Opelka, F. G., et al. (2002). The safety and efficacy of the artificial bowel sphincter for fecal incontinence. Diseases of the Colon and Rectum, 45(9), 1139-53. [DOI:10.1007/s10350004-6381-z] [PMID]

Yousefifard, M., Baikpour, M., Ghelichkhani, P., Asady, H., Darafarin, A., \& Esfahani, M. R. A., et al. (2016). Comparison of ultrasonography and radiography in detection of thoracic bone fractures; A systematic review and meta-analysis. Emergency, 4(2), 55-64. [PMID] [PMCID]

Yousefifard, M., Baikpour, M., Ghelichkhani, P., Asady, H., Nia, K. S., \& Jafari, A. M., et al. (2016). Screening performance characteristic of ultrasonography and radiography in detection of pleural effusion; A meta-analysis. Emergency, 4(1), 1-10. [PMID] [PMCID]

Yousefifard, M., Nasirinezhad, F., Manaheji, H. S., Janzadeh, A., Hosseini, M., \& Keshavarz, M. (2016). Human bone marrowderived and umbilical cord-derived mesenchymal stem cells for alleviating neuropathic pain in a spinal cord injury model. Stem Cell Research \& Therapy, 7(1), 36. [DOI:10.1186/s13287016-0295-2] [PMID] [PMCID]

Yousefifard, M., Rahimi-Movaghar, V., Baikpour, M., Ghelichkhani, P., Hosseini, M., \& Jafari, A., et al. (2017). Early versus late spinal decompression surgery in treatment of traumatic spinal cord injuries; A systematic review and metaanalysis. Emergency, 5(1), e37. [PMID] [PMCID]

Youssef, T., Youssef, M., Thabet, W., Lotfy, A., Shaat, R., \& Abd-Elrazek, E., et al. (2015). Randomized clinical trial of transcutaneous electrical posterior tibial nerve stimulation versus lateral internal sphincterotomy for treatment of chronic anal fissure. International Journal of Surgery, 22, 143-8. [DOI:10.1016/j.ijsu.2015.08.033] [PMID] 
This Page Intentionally Left Blank 